\title{
National Estimates of Advice to Quit and Child-Focused Smoking Counseling Provided to Parents Who Smoke
}

\author{
Maya Venkataramani, MD, MPH' , Barry S. Solomon, MD, MPH², Tina L. Cheng, MD, MPH', and \\ Craig Evan Pollack, MD, MHS
}

'Division of General Internal Medicine, Johns Hopkins University School of Medicine, Baltimore, MD, USA; ${ }^{2}$ Division of General Pediatrics and Adolescent Medicine, Johns Hopkins University School of Medicine, Baltimore, MD, USA; ${ }^{3}$ Department of Pediatrics, Johns Hopkins University School of Medicine, Baltimore, MD, USA.

KEY WORDS: smoking cessation; family health; ambulatory care.

J Gen Intern Med 33(5):590-2

DOI: $10.1007 / \mathrm{s} 11606-018-4382-1$

(c) Society of General Internal Medicine 2018

\section{INTRODUCTION}

Parents who smoke place both themselves and their children at increased risk for developing multiple health problems, ${ }^{1}$ and both adult and pediatric clinical practice guidelines recommend that healthcare providers counsel parents who smoke regarding smoking cessation., 3 Advice from healthcare providers may focus on the harms towards a parent's own health, but may also highlight the deleterious effects of secondhand smoke exposure on children. The extent to which parents who smoke receive these different counseling messages remains largely unknown. Using nationally representative data, we characterized how often parents receive certain types of counseling from healthcare providers and factors correlated with counseling receipt.

\section{METHODS}

We analyzed data from the Medical Expenditure Panel Survey (MEPS), a nationally representative survey of the non-institutionalized US population, from 2010 to 2014. We included primary respondents ages 18 to 64 who were self-reported smokers at the time of surveying and who were identified as the mother or father of at least one child (age 0 to 17 years) living in the household. Adult smokers were asked about advice to quit with the question: "In the past 12 months, did a doctor advise you to stop smoking?" For each child, primary respondents were asked, "Has a doctor or other health provider ever given you advice about how smoking in the house can be bad for [the child's] health?" We classified parents as receiving child-focused counseling if they reported receiving this advice for any of their children during the past 12 months. We used separate multivariable logistic regression analyses to explore correlates of receiving (1) advice to quit and (2) childfocused counseling. All analyses took into account the complex design of the MEPS.

\section{RESULTS}

Of 17,821 parents in our sample with smoking status information, 2999 reported smoking (weighted percentage of $17.1 \%$, corresponding to a weighted sample of $27,728,644$ smokers). In this subset, the majority were female $(78.3 \%)$, white $(79.6 \%)$, non-Hispanic $(89.5 \%)$, and from lower income households $(56.7 \%$ with incomes $<200 \%$ Federal Poverty Limit) (Table 1). $19.6 \%$ had at least one child with asthma. More than one quarter $(28.4 \%)$ denied receipt of any counseling. $55.3 \%$ reported receiving general counseling, and $43.8 \%$ reported counseling regarding at least one child (Fig. 1). In multivariable logistic regression analyses, females, those with a usual source of medical care, insurance, or history of cancer or heart disease, were more likely to receive advice to quit (Table 1). Parents of young children, children with asthma, and AfricanAmerican parents were more likely to report receiving child-focused counseling.

\section{DISCUSSION}

Given the adverse effects on their own health and their children's health, parents who smoke represent a unique

Published online March 14, 2018 
Table 1 Sample Characteristics and Correlates of Cessation Counseling

\begin{tabular}{|c|c|c|c|}
\hline & \multirow{3}{*}{ 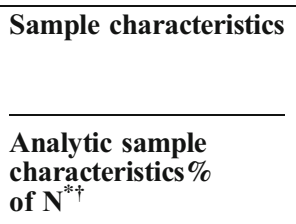 } & \multirow{2}{*}{\multicolumn{2}{|c|}{$\begin{array}{l}\text { Results of multivariable logistic regression }{ }^{*} \\
\text { Odds ratio ( } 95 \% \text { confidence interval) }\end{array}$}} \\
\hline & & & \\
\hline & & Advice to quit ${ }^{\S}$ & Child-focused counseling*| \\
\hline \multicolumn{4}{|l|}{ Characteristics of parents } \\
\hline \multicolumn{4}{|l|}{ Gender } \\
\hline Male & 21.7 & Ref & Ref \\
\hline Female & 78.3 & $1.76(1.27$ to 2.43$)$ & $1.37(0.98$ to 1.91$)$ \\
\hline Age in years (mean) & 36.5 & $1.01(0.95$ to 1.67$)$ & $0.99(0.97$ to 1.01$)$ \\
\hline \multicolumn{4}{|l|}{ Educational attainment } \\
\hline Less than grade 12 & 18.0 & Ref & Ref \\
\hline Grade 12 & 25.8 & $0.95(0.69$ to 1.31$)$ & $0.91(0.68$ to 1.21$)$ \\
\hline Any college & 41.7 & $1.26(0.95$ to 1.67$)$ & $0.96(0.72$ to 1.28$)$ \\
\hline \multicolumn{4}{|l|}{ Race } \\
\hline White & 79.6 & Ref & Ref \\
\hline Black & 14.7 & $1.22(0.94$ to 1.57$)$ & 1.21 (1.02 to 1.70$)$ \\
\hline Asian/Pacific Islander & 2.4 & $0.99(0.51$ to 1.89$)$ & $1.04(0.57$ to 1.89$)$ \\
\hline Other & 3.4 & $0.98(0.52$ to 1.86$)$ & $1.55(0.84$ to 2.87$)$ \\
\hline Hispanic ethnicity & 89.5 & $1.22(0.95$ to 1.57$)$ & $1.17(0.84$ to 2.87$)$ \\
\hline Has usual source of care & 72.3 & $2.44(1.80$ to 3.30$)$ & $1.19(0.89$ to 1.58$)$ \\
\hline Uninsured throughout year & 19.2 & $0.46(0.33$ to 0.66$)$ & $0.75(0.56$ to 1.01$)$ \\
\hline Asthma & 12.0 & $1.11(0.75$ to 1.65$)$ & $1.46(1.01$ to 2.12$)$ \\
\hline Chronic lung disease $\mathrm{e}^{\mathrm{II}}$ & 6.0 & $1.53(0.88$ to 2.66$)$ & $1.32(0.79$ to 2.22$)$ \\
\hline Heart disease ${ }^{\mathbb{I}}$ & 11.6 & $1.50(1.06$ to 2.11$)$ & $1.28(0.94$ to 1.76$)$ \\
\hline Cancer diagnosis ${ }^{\mathrm{T}}$ & 6.2 & $1.83(1.18$ to 2.82$)$ & $1.33(0.79$ to 2.22$)$ \\
\hline \multicolumn{4}{|l|}{ Family income, $\%$ of FPL ${ }^{\#}$} \\
\hline $200 \% \mathrm{FPL}$ and greater & 43.3 & Ref & Ref \\
\hline 100 to less than $200 \%$ FPL & 24.2 & $0.85(0.62$ to 1.17$)$ & $1.18(0.86$ to 1.60$)$ \\
\hline Less than $100 \%$ FPL & 32.5 & $0.87(0.70$ to 1.12$)$ & $1.36(0.98$ to 1.89$)$ \\
\hline Number of children (mean, [range]) & $1.7(1$ to 9$)$ & $0.89(0.78$ to 1.04$)$ & 1.25 (1.08 to 1.45$)$ \\
\hline Any child ages 0 to 3 years** & 28.4 & $1.23(0.86$ to 1.12$)$ & 1.74 (1.28 to 2.37$)$ \\
\hline Any child ages 4 to 12 years $* *$ & 63.9 & $1.02(0.72$ to 1.44$)$ & $0.86(0.59$ to 1.24$)$ \\
\hline Any child ages 13 to 17 years** & 39.0 & $1.09(0.78$ to 1.53$)$ & $0.83(0.57$ to 1.22$)$ \\
\hline Any child with asthma diagnosis & 19.6 & $1.01(0.76$ to 1.35$)$ & $1.42(1.10$ to 1.82$)$ \\
\hline Any child without insurance throughout year & 5.7 & $0.87(0.52$ to 1.45$)$ & $0.77(0.44$ to 1.37$)$ \\
\hline Any child without a usual source of care & 10.9 & $1.07(0.69$ to 1.65$)$ & $0.49(0.34$ to 0.70$)$ \\
\hline
\end{tabular}

$* N=2999$ unweighted [27,728,644 weighted individuals]

Or mean as otherwise specified

*logistic regression models include covariates for whom results are reported

${ }^{\S}$ Outcome defined as receiving any advice to quit versus no advice to quit; $N=2412$ unweighted [22,656,667 weighted] individuals

'Outcome defined as any child-health directed counseling versus no child-health directed counseling; $N=2467$ unweighted [23,012,148 weighted] individuals

"Reference group: not having the co-morbidity; chronic lung disease includes reported diagnoses of emphysema and chronic bronchitis; heart disease includes diagnoses of angina, coronary heart disease, myocardial infarction, stroke and angina

${ }^{\#}$ FPL $=$ Federal Poverty Level

**Reference group: not having a child in the age group

Italicized odds ratios indicate values for which $p<=0.05$

population of adults to target for smoking cessation counseling. Unfortunately, many report not receiving advice to quit or child-focused counseling, consistent with prior studies, ${ }^{4} 5$ and over $28 \%$ received no counseling at all. We found that while parental access-to-care measures correlated with receipt of advice to quit, they did not correlate with child-focused counseling receipt; also, almost one fifth received only child-focused counseling. To the extent that child-focused counseling is delivered in pediatric settings, this highlights the potential of leveraging contacts with the pediatric setting to reach adult smokers with limited healthcare access for themselves, a strategy which has been shown to be effective in interventions involving counseling and referral to cessation services. ${ }^{6}$ At the same time, overall child-focused counseling rates are low, perhaps reflecting multiple barriers to addressing 


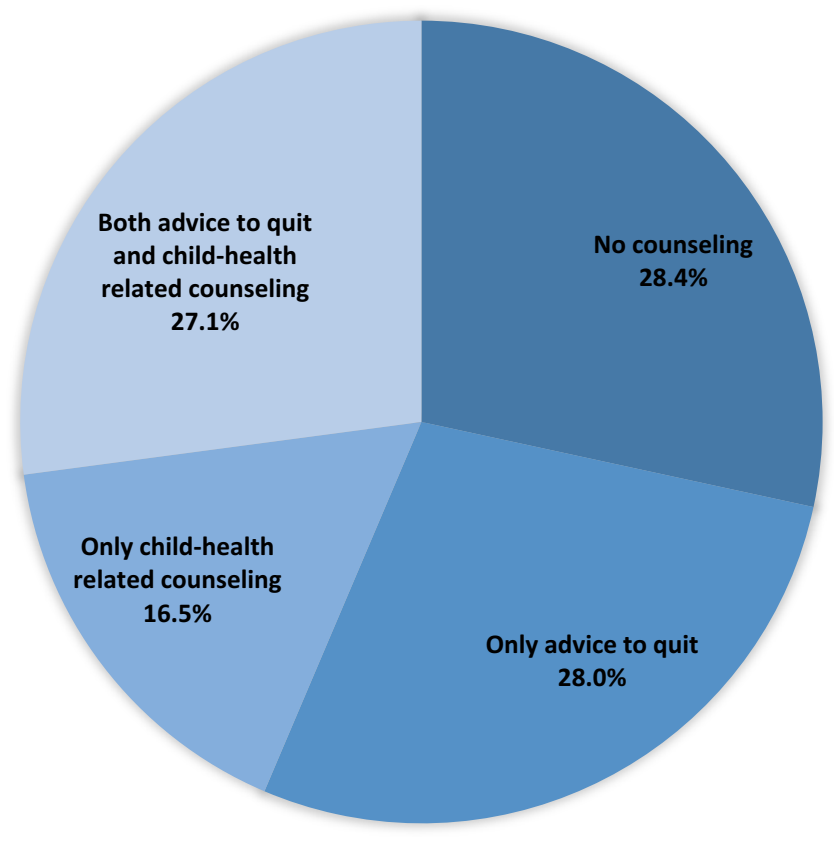

Figure 1 Frequency of cessation counseling received, by type.

parental smoking in pediatric settings. ${ }^{5}$ While this study is based on self-reported measures which may be prone to recall bias, it highlights multiple "missed opportunities" to address parental smoking in the healthcare setting. Improving overall rates of counseling, supporting pediatric settings in providing services to parents who smoke, and determining whether advice to quit provided in the context of parents' health or child-focused messaging leads to differential cessation rates are important next steps.
Corresponding Author: Maya Venkataramani, MD, MPH; Division of General Internal Medicine, Johns Hopkins University School of Medicine, Baltimore, MD, USA (e-mail: mvenkat2@jhmi.edu).

Funding Information $M$. Venkataramani was supported by an institutional National Research Service Award (T32HP10025BO) during the completion of this work.

\section{Compliance with ethical standards:}

Conflict of interest: The authors declare that they do not have a conflict of interest.

\section{REFERENCES}

1. US Department of Health and Human Services, Centers for Disease Control and Prevention, National Center for Chronic Disease Prevention and Health Promotion, Office on Smoking and Health, The Health Consequences of Smoking-50 years of Progress: A Report of the Surgeon General. Atlanta, GA, 2014. p. 17

2. Hagan J, Shaw J, Duncan P, editors. Bright Futures: Guidelines for Health Supervision of Infants, Children, and Adolescents/. Third ed. Elk Grove Village, IL: American Academy of Pediatrics; 2008.

3. United States Preventive Services Task Force. Final Update Summary: Tobacco Smoking Cessation in Adults, Including Pregnant Women: Behavioral and Pharmacotherapy Interventions. September 2015. https://www.uspreventiveservicestaskforce.org/Page/Document/ UpdateSummaryFinal/tobacco-use-in-adults-and-pregnant-womencounseling-and-interventions 1

4. King BA, Dube SR, Babb SD, McAfee TA. Patient-reported recall of smoking cessation interventions from a health professional. Prev Med. 2013(57): 715-717.

5. Nabi-Burza E, Winickoff JP, Finch S, Regan S. Triple Tobacco Screen Opportunity to Help Families Become Smokefree. Am J Prev Med. 2013 Dec;45(6): https://doi.org/10.1016/j.amepre.2013.07.007.

6. Winickoff JP, Park ER, Nabi-Burza E, Chang Y, et al. Implementation of a parental tobacco control intervention in pediatric practice. Pediatrics. 2013 (132): 109-117. 